\title{
ANALYSIS OF THE CONDITION OF A PIPE FIXED IN A CLAMPING DEVICE
}

\author{
Emin Musa Afandiyev \\ Department of Industrial engineering ${ }^{l}$ \\ ertef4@gmail.com \\ Mahammadali Nuraddin Nuriyev \\ Department of Industrial engineering ${ }^{I}$ \\ mehman62@mail.ru \\ ${ }^{1}$ Azerbaijan State Economic University (UNEC), \\ 6 Istiglaliyyat str., Baku, Azerbaijan, AZ 1001
}

\begin{abstract}
Due to the fact that clamping devices are widely used in various industries, the requirements for the operation of such devices are constantly increasing. This is due to an increase in the general requirements for processing accuracy, as well as an increase in the forces acting on the clamped part. The reliability of these devices when working with thin-walled cylindrical parts is of great importance.

Thin-walled cylinders used in mechanical engineering are subject to significant loads. With prolonged exposure to loads from clamping forces, as well as from axial tensile forces, plastic deformations of cylindrical parts occur. In the oil and gas industry, when clamping drill and casing pipes in some areas in the capture zone, stresses exceed the yield strength. Multiple clamping of the pipe will reduce the pipe wall in the gripping area, which causes premature pipe failure. Therefore, increasing the holding capacity of clamping mechanisms is relevant.

Analysis of broken drill pipes, which have been operating in wedge grips for a long time, showed that in most cases the pipes undergo plastic deformation caused by damage to the pipe surface by the teeth of the ram. To clarify the actual conditions of loading the pipe and the possibilities of increasing the capacity of the clamping devices, studies of the contact pressures in the clamping zone were carried out.
\end{abstract}

A new pipe clamping chuck is also presented, which provides a sufficiently high reliability of fastening of cylindrical parts.

Keywords: pipe, load, stress, deformation, holding capacity, cartridge, clamp, paper gauge.

DOI: $10.21303 / 2461-4262.2021 .001587$

\section{Introduction}

A feature of the operation of thin-walled cylindrical parts, in particular, drill pipes, is the susceptibility to significant deformations during the process of being gripped by clamping mechanisms. As a rule, the clamping forces are applied multiple times in the same area of the pipe. In this case, the compressive stresses can exceed the yield strength of the pipe metal. This results in local plastic deformations in the gripping zone of the pipe in the clamping mechanism. The shape and dimensions of the elements of the clamping mechanisms also have a significant effect on the nature of the pipe deformations and stresses, as well as the holding capacity of the clamping devices. This is due to the nature of the distribution of contact pressures on the surfaces of the parts of the clamping device.

With long-term operation of pipes under these conditions, such deformations lead to a thinning of the pipe wall, which creates the danger of breaking the pipe string. Drill string breakage accidents require high costs to retrieve the string or lead to abandonment of the well. The oil and gas industry is constantly experiencing a need to improve the quality of drilling equipment, especially drill and casing pipes. This is due to the high labor intensity and energy consumption of oil and gas production. Improving the quality of drilling equipment is aimed at extending the service life of pipes in order to eliminate the possibility of emergencies. This explains the relevance of the presented work.

Investigation of the distribution of contact pressures on the surfaces of parts of the clamping device, which affect the state of the pipe and the holding capacity of the clamping devices, is an important task for the oil and gas production, machine building and other industries. 
Reliability and durability of clamping devices when working with thin-walled cylindrical parts is of great importance, both in mechanical engineering and in the oil and gas industry. Therefore, the study of issues of increasing the holding capacity of clamping mechanisms is an important task.

\section{Literature review and problem statement}

Requirements for the quality of drill pipes are due to the high labor and energy consumption of oil production. Improving the quality of drilling equipment, in particular, clamping mechanisms, extends the service life of drill pipes in order to eliminate the possibility of emergencies. Work in this direction is of great practical importance.

In work [1], some technological methods for improving the quality of pipes are considered, as well as design features of some clamping devices used in round-trip operations when drilling wells. However, no attention has been paid to damage to the pipe surface by clamping jaws.

In work [2] it is shown that pipe damage during tripping operations occurs mainly from the action of clamping jaws. The condition of the pipe in the clamping device is also influenced by various factors, such as clamping force, radial and axial loads, column mass. It is noted that the most uniform distribution of forces along the teeth of the clamping jaws is provided by an oblique intersecting notch, which gives a high holding capacity of the clamping devices.

Drill-pipe clamping mechanisms have also been investigated by the American Petroleum Institute (API). In the API standards, it is noted that deformations of drill pipes occur due to cuts on their surface, which are left by teeth of wedge rams or drill tongs [3].

Work [4] is devoted to the study of thin-walled cylindrical parts. The paper considers external factors affecting the stress state of a cylindrical part. The adhesion coefficients in the clamping devices were analyzed. Methods for improving the design of their elements are proposed in order to increase the adhesion coefficients. However, not all influencing factors are taken into account.

The paper [5] describes the properties of paper used as a sensor when measuring contact pressures.

In works $[6,7]$ external factors influencing the stress state of the pipe are considered. The coefficients of adhesion in the clamping devices are analyzed. Methods for improving the design of their elements are proposed in order to increase the adhesion coefficients.

In work [8] it is shown to what deformations the pipe is subject during operation. The processes of material creep are considered, which can be, as a consequence of stress relaxation under sufficiently long exposure to high stresses. These processes, considered in the work, show that in order to increase the holding capacity of the clamping mechanisms, it is necessary to comprehensively study all the factors affecting the deformation of the drill pipe during tripping operations.

In the material [9], a new pipe clamping chuck is presented, which provides reliable pipe clamping during processing.

In other works, the influence of structural elements of clamping devices on the stress state and deformation of the pipe has also been investigated, and recommendations are given for improving their design in order to increase the holding capacity [10, 11].

In the literature presented, insufficient attention is paid to recommendations for reducing stresses and deformations when fastening thin-walled cylindrical and other similar parts in clamping devices. There are practically no dependencies for engineering calculations and analysis of loading schemes.

\section{The aim and objectives of research}

The aim of this research is to identify the nature of the distribution of contact pressures on the surfaces of the parts of the wedge-clamping mechanism and its effect on the loads acting on the pipe. The equalization of the distribution of the load on the pipe helps to reduce deformations of the drill pipes during tripping operations and to increase the holding capacity of the clamping devices.

For this aim, it is necessary to solve the following objectives:

- to determine the nature of the distribution of the contact load from the axial force along the wedges and clamping jaws to reduce pipe deformation;

- to determine the possibility of ensuring high reliability of clamping of the processed cylindrical parts using a new design of the clumping device. 


\section{Study of factors affecting the state of the pipe in the clamping mechanism}

4. 1. The nature of the distribution of contact pressures on the surfaces of wedges and clamping jaws

The working condition of drill pipes and their permissible weight during tripping operations depends on the design of the clamping device. This is due to the nature of the distribution of the loads that are created by this device.

In studies of the nature of the distribution of contact pressures, the method of prints was applied, based on the change in the transparency of the paper as a result of its squeezing. In the experiment, let's use high quality writing paper withstanding pressures in the range of 0-500 $\mathrm{MPa}$, the optical non-uniformity of which does not exceed $1.5 \mu \mathrm{A}[5]$.

When analyzing contact pressures in this way, special friction conditions are created between surfaces. In this case, the frictional forces have a great influence on the horizontal and shear stresses. At the same time, such influence on the distribution of contact pressures is small. Therefore, when studying the distribution of contact pressures, the dynamics of friction can be neglected. The experiments were carried out on a specially designed stand (Fig. 1), equipped with hydraulic jacks, which simulates the operation of the clamping device during hoisting operations.

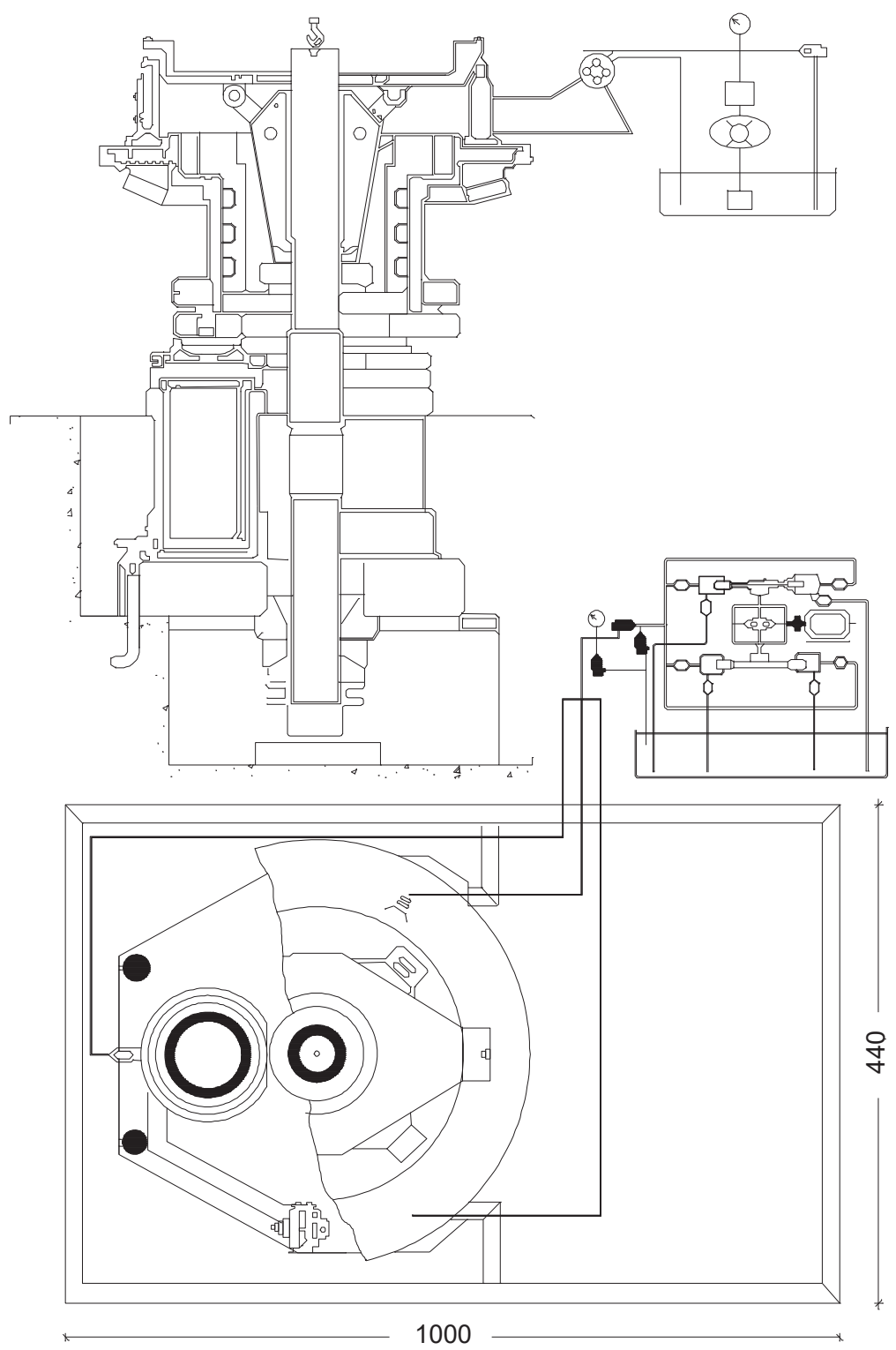

Fig. 1. Hydraulic stand 
The stand is installed in a concrete pit $1.8 \mathrm{~m}$ deep, $2.2 \mathrm{~m}$ and $1.2 \mathrm{~m}$ in size. On the ledge of the foundation, a plate with a thickness of $180 \mathrm{~mm}$ is installed and fixed with four anchor bolts, which serves as the base of the stand. There are 3 cylinders of the GDZ-300 jack on the plate. On the pistons of the jack, 3 feet with spherical heads are installed, forming a hinge joint. The plate prevents the heels from moving relative to the head.

A plate is installed on the projections of the spherical heads, on which the rotor table is laid. The main parts of the wedge gripper are installed in the rotor table. The working pressure is created by the pumping unit of the hydraulic jack GDZ-300. The working fluid of the jack is Industrial oil 30.

After reaching the required effort, the pumping unit is turned off. To relieve the load, the drain valve opens and the oil returns to the tank.

The stand is capable of creating a longitudinal axial load on the pipe up to 450 tons. As an experimental sample, let's use a branch pipe from a drill pipe with a diameter of $141 \mathrm{~mm}$ and a wall thickness of $10 \mathrm{~mm}$ made of steel of strength group E.

The object of research were wedges and liners, as well as clamping jaws with an inner cylindrical surface. Standard A4 size paper sheets were placed between the wedge and the liner under the wedge support plane; between the wedge and dies; as well as between the ends of adjacent dies (Fig. 2). In all cases, a sheet of paper, which is actually a contact pressure sensor, was placed between two sheets of paper of the same brand to protect against impurities.

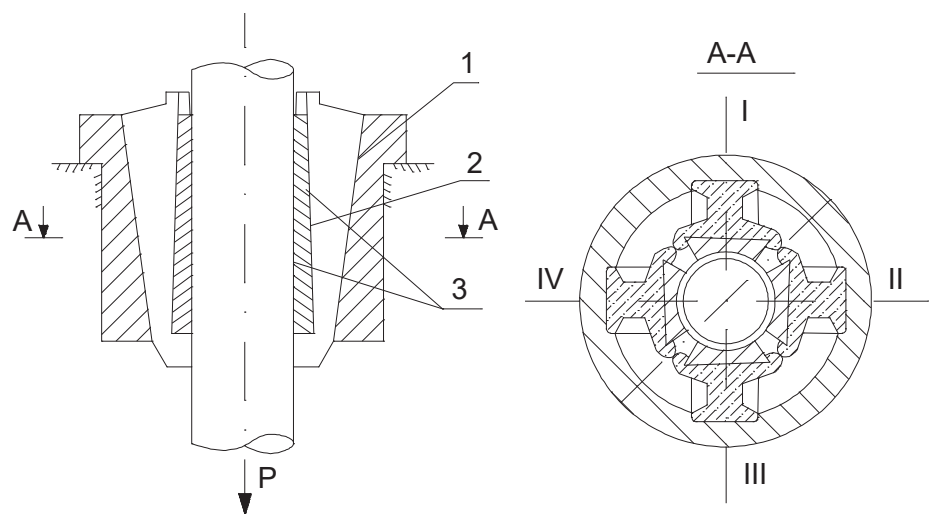

Fig. 2. Location of the pipe in the wedge grip

The surfaces of the clamping unit that come in contact with the paper sensors were thoroughly cleaned of grease. Considering that the lack of lubrication could lead to seizure on the wedge bearing surfaces, paper sensors were placed under each wedge in turn, and the bearing planes of the remaining wedges were coated with graphite grease.

The axial tensile force $\mathbf{P}$ in each experiment was adjusted to $10 \mathrm{kN}$. After reaching the specified load, the installation was unloaded, the paper gauges were released, and the contact pressures were measured on all surfaces (Fig. 3). Measurements were taken immediately after unloading, considering that paper probes can induce stress relaxation.

It has been experimentally established that the pressures on the supporting surfaces of the wedges are unevenly distributed. In particular, contact pressures of up to $300 \mathrm{MPa}$ are noted in the lower layers of the support plane, as well as in the lower parts of the surfaces of the backs of the lower jaw. The highest pressures are noted at the ends of the lower jaw, which takes up the entire axial load. The ends of the middle and upper jaws are practically unloaded.

Due to the fact that the load on each wedge was the same, the dynamics was not taken into account here. The results were recorded after reaching the specified load and clearly reflected on the paper sensors due to the change in density. This made it possible to obtain a clear picture of the distribution of contact pressures on the surfaces of the clamping device elements.

Uneven pressure distribution is a consequence of the influence of the design features of the clamping mechanism, as well as some technological factors, such as manufacturing and assembly accuracy, the macro geometry of contact surfaces, etc. As a result of the uneven pressure distri- 
bution, contact and volumetric deformations of the pipe significantly increase. This can lead to its premature failure. It is possible to reduce the unevenness of the pressure distribution by using self-aligning wedges and dies with an oblique intersecting notch [4].
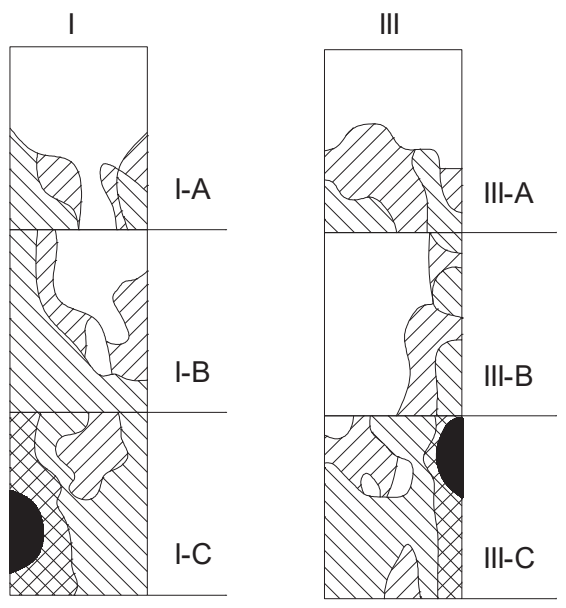

I-A

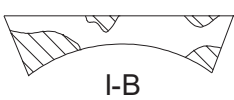

I-B

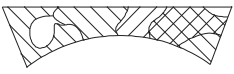

I-C

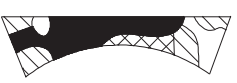

III-A

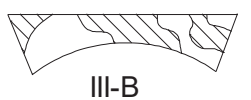

-B

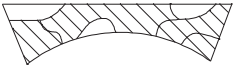

III-C

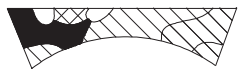

Fig. 3. Distribution of pressure among the elements of clamping devices

\section{2. Improving the reliability of fastening cylindrical parts}

The design of the clamping device plays an important role in increasing the reliability of the fastening of cylindrical parts. In this regard, a new pipe clamping chuck was proposed, which can be used on pipe-working and coupling-screwing machines.

The pipe clamping chuck presented here provides a sufficiently high reliability of fastening of cylindrical parts. This is achieved due to the fact that the chuck is equipped with cams with shoes, which provide the possibility of rotation. The wedges are fixed in the grooves of the cams and interact with the support rollers of the liners (Fig. 4). The chuck drive mechanism includes a power cylinder and a lever self-braking transmission 2, cams 3 installed in the housing 4. Curved wedges 5 are fixed in the grooves of the cams and contact with support rollers 6 , which are located in the liners 7 located in the pads 8 . In the liners 7 installed floating jaws 9. Pads 8 are located in cams 3 and are under the action of return springs 10. Pads 8 are installed in cams 3 on rollers 11.

The principle of operation of the cartridge is as follows. When pressure enters the rod cavity of the power cylinder, the cams through curved wedges and support rollers press the liners with jaws to the pipe. The pads move and the pipe is pre-clamped. The clamping jaws fit snugly against the pipe surface as they align themselves (Fig. 5).

Further, when the pipe is screwed on under the action of a torque, it turns together with the jaws and liners. In this case, the support rollers are rolled on curved wedges fixed in the cams, while the liners begin to move towards the center, and perform an additional clamping of the pipe. The clamping force is proportional to the effective torque.

After processing the pipe, pressure is applied to the piston cavity of the cylinder. The cams move apart, and the springs return the pads with liners to their original position. In order to prevent the pads from falling out of the cams, rollers are installed on them. 


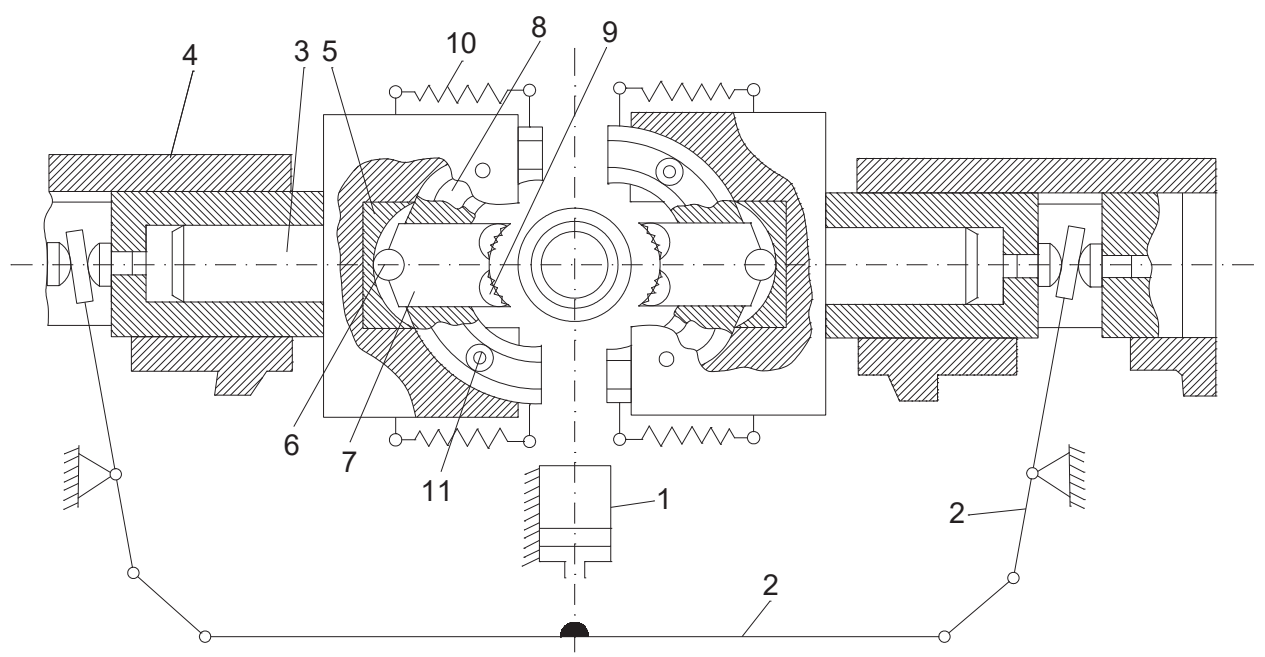

Fig. 4. Pipe clumping chuck

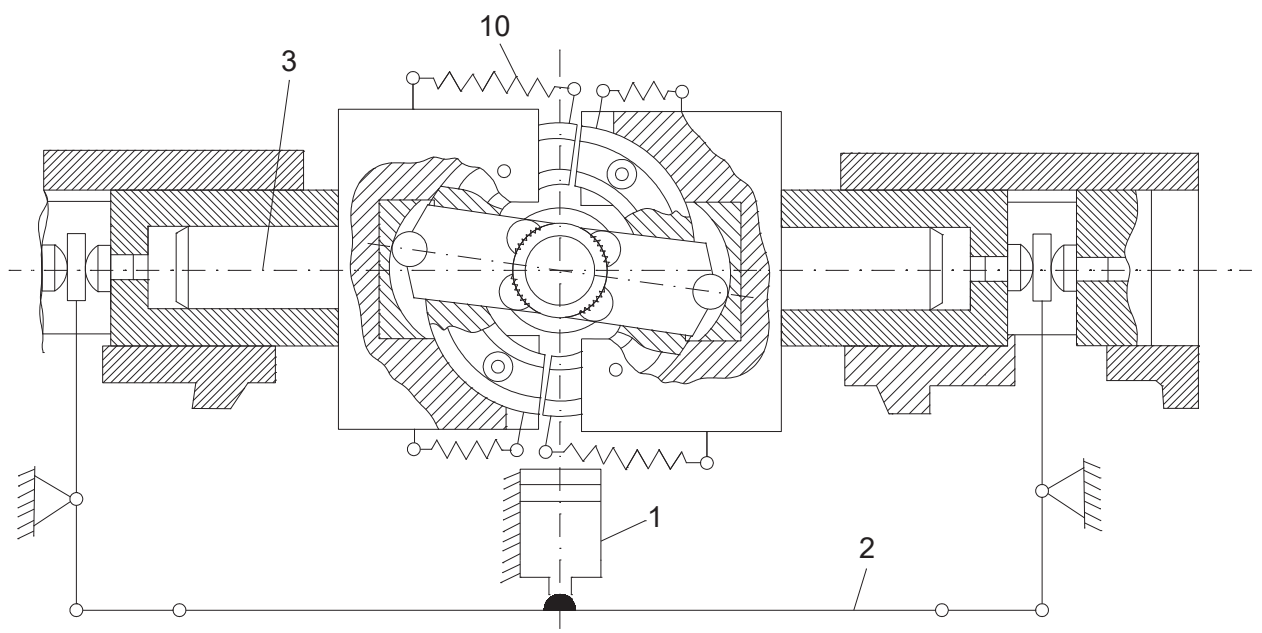

Fig. 5. Clamping chuck in clamping state

The pre-clamping of the pipe provides the amount of adhesion of the jaws that is necessary for a secure grip and prevention of rotation under the main load. The pre-clamping force can be adjusted by the pressure in the cylinder of the drive mechanism. The effectiveness of this device is ensured by the high reliability of fixing the processed cylindrical parts. The presented pipe clamping chuck is protected by copyright certificate No. 910370.

\section{Discussion of the research results of pressure distribution over the elements of clamping devices}

In the oil and gas industry, when clamping drill and casing pipes in the capture zone, stresses often exceed the yield strength. Multiple clamps in the same area of the pipe cause the pipe wall to shrink, leading to premature pipe failure.

As a rule, the clamping forces act in the same area of the pipe. In some cases, compressive stresses cause local plastic deformations in the gripping zone of the pipe in the clamping mechanism. The shape and dimensions of the elements of the clamping mechanisms also have a significant influence on the nature of the pipe deformations and stresses, as well as on the holding capacity of the clamping devices. This is due to the nature of the distribution of contact pressures on the surfaces of the parts of the clamping device.

In studies of the distribution of contact pressures, the method of prints was applied, based on the change in the translucency of paper as a result of its squeezing. The experiments were 
carried out on a stand that simulates the operation of the clamping device in the process of round-trip operations (Fig. 1). In the wedge grip, 4 wedges, each equipped with three dies, simultaneously grip the pipe under the action of a clamping force. Subsequently, from the axial load (from the weight of the column), the final clamping of the pipe occurs. In this case, the parts of the clamping device are subjected to contact pressure at the joints. The results of squeezing paper sensors at different gripping points are shown in (Fig. 3). The results obtained are explained by the fact that the pressures on the supporting surfaces of the wedges are unevenly distributed. The highest pressures are noted at the ends of the lower jaw, which takes up the entire axial load.

The uneven distribution of pressures is a consequence of the influence of the design features of the clamping mechanism, in particular, the presence of a large number of joints, as well as some technological factors, such as the macro geometry of the contact surfaces, etc. At the moment, this problem has not been fully solved.

The limitations of this study are that drill pipes are its object, since they are most susceptible to deformations from axial and radial loads during tripping operations. However, despite the fact that the research carried out refers to drill pipes, the main conclusions can be applied to other cylindrical parts.

The design of the clamping device plays an important role in increasing the reliability of the clamping of cylindrical parts during processing. In this regard, a new pipe-clamping chuck was proposed, which can be used on pipe-working and coupling-screwing machines (Fig. 4). The effectiveness of this device is ensured by the high reliability of fixing the processed cylindrical parts.

Further development of this study can be continued taking into account other types of loads and different pipe materials.

\section{Conclusions}

As a research result, it was found that the pressure on the supporting surfaces of the wedges is distributed unevenly. In particular, contact pressures of up to $300 \mathrm{MPa}$ are noted in the lower layers of the support plane, as well as in the lower parts of the surfaces of the backs of the lower jaw. The highest pressures are noted at the ends of the lower jaw, which takes up the entire axial load. The ends of the middle and upper jaws are practically unloaded.

In order to increase the reliability of the fastening of cylindrical parts during processing, a new pipe clamping chuck has been proposed, which can be used on pipe processing and couplingscrewing machines.

\section{Acknowledgement}

We express our gratitude to Professor I. Lopatukhin for his idea and participation in the creation of the pipe clumping chuck and other consultations.

\section{References}

[1] Markov, O., Gerasimenko, O., Khvashchynskyi, A., Zhytnikov, R., Puzyr, R. (2019). Modeling the techological process of pipe forging without a mandrel. Eastern-European Journal of Enterprise Technologies, 3 (1 (99)), 42-48. doi: https://doi.org/ 10.15587/1729-4061.2019.167077

[2] Afandiyev, E. M., Nuriyev, M. N. (2019). Studying the quality of drill pipes clamped in a wedge clamp. Eastern-European Journal of Enterprise Technologies, 4 (7 (100)), 16-21. doi: https://doi.org/10.15587/1729-4061.2019.174494

[3] Rukovodstvo po trubam neftyanogo sortamenta i ih soedineniyam, primenyaemym za rubezhom (1969). Moscow: Nedra, 296.

[4] Afandiyev, E. M., Nuriyev, M. N. (2020). Improving the retention capacity of clamping elements. Eastern-European Journal of Enterprise Technologies, 1 (1 (103)), 47-51. doi: https://doi.org/10.15587/1729-4061.2020.195193

[5] Rozanov, B. V., Lints, V. P., Shchegoleva, V. P. (1978). Svoystva bumagi, ispol'zuemoy v kachestve datchika pri izmerenii kontaktnyh davleniy. Vestnik mashinostroeniya, 12, 73-75.

[6] Wang, L., Guo, S., Gong, H., Shang, X. (2016). Research and development of a self-centering clamping device for deepwater multifunctional pipeline repair machinery. Natural Gas Industry B, 3 (1), 82-89. doi: https://doi.org/10.1016/ j.ngib.2015.12.012 
[7] Djukic, L. P., Sum, W. S., Leong, K. H., Hillier, W. D., Eccleshall, T. W., Leong, A. Y. L. (2015). Development of a fibre reinforced polymer composite clamp for metallic pipeline repairs. Materials \& Design, 70, 68-80. doi: https://doi.org/10.1016/ j.matdes.2014.12.059

[8] Markov, O., Gerasimenko, O., Aliieva, L., Shapoval, A. (2019) Development of the metal rheology model of high-temperature deformation for modeling by finite element method. EUREKA: Physics and Engineering, 2, 52-60. doi: https:// doi.org/10.21303/2461-4262.2019.00877

[9] Efendiev, E. M., Lopatuhin, I. M. (1982). Trubozazhimnoy patron. Avtorskoe svidetel'stvo SSSR No. 910370. Byulleten' izobreteniy, 9.

[10] Yakhin, A. R., Ismakov, R. A., Garifullin, R. R., Yangirov, F. N. (2014). Surface hardening for drill pipe life improvement. Oil and Gas Business, 4, 381-399. doi: https://doi.org/10.17122/ogbus-2014-4-381-399

[11] Bulatov, A. I., Proselkov, Yu. M., Shamanov, S. A. (2013). Tehnika i tehnologiya bureniya neftyanyh i gazovyh skvazhin. Moscow, 1007. Available at: https://www.geokniga.org/books/12460

Received date 12.11.2020

Accepted date 20.01.2021

Published date 29.01.2021
(C) The Author(s) 2021

This is an open access article under the CC BY license (http://creativecommons.org/licenses/by/4.0). 